\title{
DOSSIÊE
}

Sociologias, Porto Alegre, ano 10, no 19, jan./jun. 2008, p. 130-177

\section{Capital social e a privatização do conhecimento}

RENATO P. SAUL*

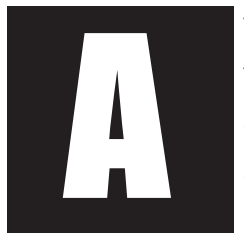

versão anglo-americana do programa da terceira via exposta por Giddens em 1998 e 2000 pode ser vista como uma espécie de superfície serena que, ao mesmo tempo, encobre e revela, ademais das peculiaridades geopolítico-econômicas do momento, a agitação intelectual que repercute de modo decisivo na reflexão científica no terreno das ciências sociais no fim do século 20. Duas das expressões mais significativas deste movimento podem ser percebidas nas questões relacionadas com a identificação de uma crise institucional na democracia americana a partir dos anos 1970 e com a verificação do processo de reconfiguração paradigmática que a Sociologia experimenta na mesma época, tendo como meio de articulação principal a ciência social desenvolvida nos Estados Unidos. A crise institucional da democracia americana, tal como vem descrita por alguns autores, tem como pano de fundo a reorganização do poder econômico do país, desenrolandose concomitantemente às suas transformações e tratada freqüentemente como resultado do fenômeno da globalização econômica. A questão do "excepcionalismo americano" é um dos aspectos mais lembrados nas análises relacionadas com as mudanças verificadas.

\footnotetext{
* Sociólogo, professor titular jubilado da UFRGS. Endereço eletrônico: rpsaul@uol.com.br
} 
Um interessante depoimento a esse respeito é patrocinado pelo historiador Colin Gordon que, precisamente, busca as razões para o tema do excepcionalismo ter deixado de ser motivo de interesse de estudiosos da história do país. Gordon examina a questão a partir da verificação de que, tomando a questão do corporativismo pelo seu viés mais popular, isto é, como uma ordem social apoiada sobre três fundamentos, o negócio, o trabalho e a política, os Estados Unidos, em termos de economia política, aparece como "o palhaço-mor do corporativismo". Qualquer que seja a perspectiva de análise que se adote em relação a padrões de organização do trabalho, dos negócios ou da política, a verificação é a mesma, domina a absoluta falta de organização (p.29, 1998).

Sustentando a escassa capacidade de organização dos setores operários americanos, que, ao longo de sua história de lutas, tanto através das suas organizações sindicais, quanto das suas federações, jamais conseguiram suficiente densidade de atuação que lhes permitisse impor políticas sociais amplas e duradouras, Gordon detém-se na tentativa de explicar o enigma que representa o poder dos negócios na definição dos destinos do país, apesar de ser também tão desorganizado. De acordo com a sua interpretação, no fundo, o conjunto do setor de negócios se beneficia da desorganização dos setores operários e da desorganização da política nacional de um modo geral. O status privilegiado do setor de negócios seria conseqüência da desorganização política dos operários e da sua própria desorganização. É uma situação um tanto insólita: de uma parte, a histórica debilidade do movimento nacional dos trabalhadores contribui para a fraqueza da organização dos negócios; de outra, a fraqueza do Estado nacional contribui para a desorganização do setor de negócios. A resultante é a dominação dos negócios. Nos termos de Gordon: "Em lugar nenhum é a política uma ameaça tão débil ao capital privado e em nenhum lugar é a retórica anti-estatista mais feroz" (ibid. p.41). Na realidade, o antiestatismo mais parece uma cortina de fumaça que encobre o seu uso pelo "setor de negócios". A explicação 
dada por Gordon, contudo, não admite uma política "corporatista industrial". Inspirando-se numa metáfora elaborada por um cientista político, Charles Lindblom, de acordo com a qual a política está aprisionada pelo mercado, Gordon assume que o que contribuiria em parte para o privilégio do setor de negócios seria a ação da "lógica genérica do capitalismo democrático", pois, "qualquer sistema de capitalismo democrático define os limites do 'capitalístico' ao redor da regra democrática" (ibid. p.33).

Um estudo de grande envergadura e repercussão a respeito da crise institucional dos Estados Unidos foi o de Robert Putnam, Bowling alone, the colapse and revival of american community, de 1995. Nele, o autor explora problemas relacionados com o envolvimento cívico e das pré-condições da democracia e da democratização na sociedade americana. A abordagem de Putnam assumirá importância decisiva na discussão das soluções políticas, em termos de uma terceira via. De modo especial, suas preocupações envolvem a questão do capital social e da confiança como tendo papel decisivo na definição dos rumos do país.

Em parte levado pelas questões levantadas por Putnam e indicando de modo categórico a dimensão que assume o tema das instituições que regem a vida política interna americana, em 1996, o consagrado cientista político Seymour Lipset lança o livro American excepcionalism, a doubleedged sword. De certa maneira, nele, Lipset retoma questões já levantadas em The politics of unreason, de 1978, explorando as contradições presentes na sociedade americana como sinais de um mundo que experimenta grandes mudanças nas últimas décadas. Conclui melancolicamente, sustentando que as virtudes do excepcionalismo americano estão nas origens dos seus problemas atuais: "O Credo Americano (...) promove um alto senso de responsabilidade, iniciativa independente e voluntarismo e também encoraja o comportamento egoísta, o atomismo e o desinteresse pelo bem estar comunitário" (p.268, 1997). 
Rechaçando argumentos como os de Putnam a respeito do declínio do "nível" de capital social como causa dos males da democracia americana, destaca-se o texto de Carl Boggs, The end of politics: corporate power and the decline of public sphere, de 1999. Segundo Boggs, a decadência da vida política americana se verifica a partir de um processo de "colonização corporativa" que, via manipulação e difusão de um ethos nacional contrário à política, esvazia a participação na vida pública, transforma os acontecimentos políticos em questões de menor significado e estimula o crescente desinteresse pelo processo eleitoral.

Outro trabalho dos mais sugestivos a respeito da degradação da vida democrática americana é o de Theda Skocpol, Diminished democracy: from membership to management in american civic life, publicado em 2003. A partir de um relatório do Council of Civil Society, orgão do Institute of American Values, datado de 1998, que havia identificado padrões declinantes na vida civil do país, a investigação de Skocpol se processa através de um minucioso exame das formas de participação política desde o voluntarismo da fase inicial da vida repúblicana. Skocpol observa que, desde a Guerra Civil até o período pós-Segunda Guerra Mundial, as associações voluntárias e a atuação do Estado do Bem-Estar estiveram intimamente ligados. Seria esta ligação o verdadeiro substrato da versão americana do keynesianismo. A maioria dos grupos voluntários era, então, muito mais do que segmentos representativos de comunidades locais. Muitas dessas associações atuaram como partes de entidades regionais e nacionais, por longo tempo, e deram sustentação a importantes programas sociais, mantidos através de recursos públicos, representando papel decisivo na organização democrática dos governos. Em meados dos anos 60, embora essas federações continuassem a desempenhar papel importante, elas gradualmente perderam espaço e significação, na medida em que passaram a entrar em ação novos movimentos sociais, com o surgimento de novos tipos de lideranças e de 
novos tipos de envolvimento, mais profissionais, no processo reivindicativo. De um modo geral, a ampliação dos movimentos sociais dos anos 60, com seu caráter popular e seu radicalismo, forçaram uma redefinição das relações entre grupos de pressão e setores governamentais. Ao lado dos movimentos por direitos civis, do movimento feminista, do movimento ambientalista, da atuação de confrarias religiosas, etc., surgiram, durante os anos 70 e 80, associações especializadas representando o do mundo dos negócios. Essas associações ganhariam maior expressão nos anos 80, passando a competir, com vantagens, com as outras organizações voluntárias em virtude de suas especializações, resultando numa transformação importante no comportamento cívico da sociedade. Cotejando opiniões otimistas e opiniões pessimistas com respeito às transformações operadas nas federações associativas e sobre sua atuação na vida política do país, Skocpol conclui que a clássica participação associativa em federações construíra uma ligação de duas mãos entre grupos e espaços e entre o local e o nacional. Na situação criada a partir dos anos 80, essas ligações começaram a deteriorar-se, em razão da ação mais eficaz de entidades centralizadas e dirigidas por especialistas. A vida cívica do país se reduze, então, cada vez mais, a uma dominação de tipo oligárquico (conforme Skocpol, cap.6, 2003).

Como se pode verificar pelas caracterizações aplicadas às transformações da organização estatal a partir do movimento de globalização, arroladas pelo investigador em administração pública Ali Farazmand, tais como "Estado corporativo", "Estado-sombra", "Estado contratante", "Estado empresarial", etc., a principal transformação diria respeito à persistência do Estado Nacional e à mudança do seu caráter administrativo. O Estado do Bem-Estar passava a caracterizar-se como "Estado corporativo", ou "corporate administrative state", como Farazmand prefere. O lado negativo da globalização econômica, no seu entender, corresponderia à ameaça à soberania dos Estados Nacionais, os constrangimentos à democracia, à concentração da estrutura de poder global, à intensificação da centralização das 
decisões nas mãos de elites empresariais e governamentais e à crescente dependência das nações menos desenvolvidas"(p.515, 1999).

A contribuição de Farazmand para a apreciação das transformações da estrutura administrativa do Estado, combinada com o debate em torno da questão relacionada com a situação da democracia e do excepcionalismo, nos Estados Unidos, traz à baila as avaliações sobre a estrutura de poder e de decisões na sociedade americana bem como sobre o papel e as funções das corporações nesse processo, tanto do ponto de vista político, como do ponto de vista social e cultural. No conjunto de manifestações que buscam caracterizar o poder real das corporações à época, a noção de command capitalism aparece como produto, não da atuação das corporações, mas das pressões exercidas por "grupos de interesses" não especificados (Monsen,1979). Contudo, nos anos noventa, a discussão em torno do tema ganhava contorno mais definido com o uso da expressão state capitalism por Seymour Melman, (1997) (autor, entre outras obras, de Pentagon capitalism e Permanent war economy, de 1970 e 1974, respectivamente) e as análises sobre o processo de globalização e as práticas das corporações transnacionais contidas em Sklair ([1995],1990 e 2002), Giovanni Arrighi ([1996], 1994), Hirst e Thompson ([1998], 1996) e outros.

Quaisquer vínculos que se estabeleçam entre as noções de "Estado corporativo", de "capitalismo estatal" e de "Estado empreendedor geral", têm como fonte transformações que, tanto no plano material, quanto no plano não material, operam na divisão internacional do trabalho a partir da expansão internacional das corporações e caracterizadas genericamente como produtos do movimento de globalização econômico-financeira. A tendência que se faz presente no interior da sociedade americana, no final do século vinte, corresponde ao resultado da nova configuração do mercado mundial e da atuação de seus principais agentes, as grandes empresas transnacionais. Ou seja, a desorganização civil da sociedade americana, tal como identificada pelos investigadores antes citados é, na realidade, o ou- 
tro lado da expansão do poder corporativo e, como tal, expressão de um outro horizonte geopolítico que se define através de uma nova conformação de blocos econômicos regionais, induzidos por esse poder. É a partir daí que se desenha o programa da terceira via, capitaneada pelos governos americano e britânico.

O movimento intelectual que envolveu a reflexão científica nas ciências sociais a partir dos anos 1960, mas cujos desdobramentos se manifestam mais incisivamente de 1980 em diante, é emoldurado por dois acontecimentos emblemáticos, o esgotamento do modelo keynesiano de política econômica e os eventos de maio de 1968 em Paris. O espectro da ciência sociológica, então, tende a decompor-se num amplo campo de alternativas programáticas. Mais de uma dezena de propostas e projetos intelectuais pode ser identificada neste contexto, importando, ora num refinamento de perspectivas, ora na pura e simples substituição de teorias e procedimentos metodológicos considerados historicamente superados. Algumas tendências podem ser identificadas como mais claras e definidas. Entre elas, a de negação das teorias clássicas, a proposição de refinamento de técnicas de investigação empírica, o fortalecimento da sociologia da cultura, a formação de programas teóricos de investigação, a composição de estudos interdisciplinares com diálogo entre diferentes tendências teórico-metodológicas, a formação de redes de colaboração em pesquisas quantitativas, ou a construção de novas sínteses teóricas para a realização de diagnósticos sobre a realidade contemporânea (conforme Giddens, p.23-51, 1987; Collins, 1986 e 1989; Camic \& Gross, 1998; Smelser, 1999; Moody, 2004).

Como se pode imaginar, neste universo de proposições domina a dispersão de esforços e muita confusão. De acordo com a apreciação de Smelser, não obstante terem surgido contribuições importantes para o desenvolvimento da disciplina, nos últimos 25 anos considerados, são visíveis, ao longo do processo, tendências à fragmentação, de um lado, e tendências à padronização das diferenças, de outro, substituindo-se velhas disputas 
entre posições epistemológicas ou éticas distintas, por uma forma de tolerância mútua, por um certo tipo de "pluralismo pacífico". Uma profunda ambivalência marca, no entender, de Smelser, o panorama sociológico do fim do século. Por uma parte, nota-se que a Sociologia se institucionalizou e se afirmou como uma empresa duradoura, mas, por outra parte, verificase a existência, em torno dela, de visível inquietação na qual desponta a sensação de perda de rumo (Smelser, p.6, 1999). Mais ou menos na mesma direção das observações de Smelser vão as considerações de Camic \& Gross (p.469-9,1998) a respeito do quadro geral da configuração paradigmática. Muito embora seja possível identificar evidências de vitalidade intelectual em alguns projetos, a avaliação do conjunto não favorece uma apreciação positiva. Predominam o pessimismo, a desilusão, a desorientação e a desorganização quanto aos rumos dos projetos.

Na verdade, quando se consideram as análises realizadas pelos autores referidos a respeito das novas direções da evolução da ciência, duas características parecem dominar neste processo, a fragmentação disciplinar e a desarticulação teórica dos projetos e propostas inovadoras de compromissos com uma perspectiva crítica da realidade social. O "pluralismo pacífico", aludido por Smelser para ilustrar essa ausência de visão crítica da sociedade contemporânea, aponta para a arquitetura de um viés conformista definindo a direção principal da Sociologia. Esta mesma sensação pode ser verificada na manifestação apreensiva de Michael Burawoy com os destinos da ciência, no fim do século vinte. Na visão de Burawoy, o pessimismo pós-moderno impregnou a Sociologia de tal modo que confundiu a teoria pós-socialista com a teoria pós-colonialista. Segundo ele, o pensamento pós-socialista tornou-se uma espécie de quinta-essência do pensamento pós-moderno em sua negação das visões utópicas como inviáveis e perigosas: "Contra esse pessimismo messiânico não necessitamos acumular mais fatos que nos amarrem a um eterno presente (...), este é um tempo (...) para uma sociologia revolucionária que reconfigure o que já conhecemos" 
(Burawoy, p.695, 2000). Não muito distante destes termos estão os argumentos do manifesto de lançamento do Journal of Classical Sociology, em 2001, investindo duramente contra a fragmentação da disciplina através da criação de sub-especializações e do desenvolvimento de estudos interdisciplinares que, absurdamente, passam a ser desprendidos das raízes lógicas contidas em suas disciplinas de origem. Além da falta de rigor intelectual derivada da prática da interdisciplinaridade em curso e seus efeitos nocivos sobre o sistema educacional, o manifesto também acentuava a descaracterização da disciplina através do seu tratamento como "teoria social" e do progressivo esvaziamento que experimentava seu conteúdo crítico (JCS, 2001).

David Owen (p.13-17, 1997) identificou dois grandes debates envolvendo a Sociologia nesse momento. Um deles compreendia a perspectiva do surgimento de uma pós-modernidade, caracterizada por um conjunto de proposições consistentes na crítica das metanarrativas e ao eurocentrismo, bem como a afirmação do antifundamentalismo e do relativismo, em especial o relativismo do discurso. O outro debate correspondia ao enfrentamento entre os que sustentavam ser o desenvolvimento contemporâneo uma tendência, no sentido da emergência de um novo sistema social no qual predominaria o caos, a indeterminação e a ambivalência, e aqueles que imaginavam serem as novas condições os sinais de surgimento de uma nova modernidade global, a modernidade reflexiva. Esses debates estão intimamente entrelaçados com as grandes discussões que envolveram a Sociologia em face da emergência do processo de globalização, seja em seus aspectos econômicos, seja nos aspectos políticos, seja nos aspectos culturais (Guillen, 2001), e eles permitem divisar algumas direções cruciais para os rumos da Sociologia no século 21.

A observação de Owen enseja descortinar um ponto de contato entre propostas aparentemente contraditórias arroladas nos debates mencionados. O elemento-chave nessa aproximação é a noção de "risco" que nucleia outras idéias que, nesta conjuntura, começam a dominar a cena teórica 
como desdobramentos de estudos em torno do processo de globalização. Uma dessas noções é a de "capitalismo desorganizado". A outra noção é a de "modernização reflexiva", cujo enunciado desenvolve-se no contexto da caracterização da "sociedade do risco".

A noção social de risco parece ocupar um espaço definitivo nas preocupações das ciências sociais na passagem dos anos 1970-80 (Krimsky \& Golding, 1992). De acordo com a observação de Ortwin Renn sobre os estudos em torno do risco desde uma perspectiva sociológica, a questão envolve duas dimensões principais. Uma primeira contrapõe perspectivas de análises individualistas e perspectivas estruturalistas, na qual se discute fundamentalmente a base individual, grupal ou institucional do risco ou o seu caráter de fenômeno que envolve problemas socioestruturais e globais não intencionais. A outra, opondo posturas objetivistas e construcionistas, comporta discussões em torno da natureza do risco e de suas manifestações. Como manifestações de fenômenos reais e observáveis ou como manifestações construídas como "artefatos sociais", fabricados por grupos sociais ou instituições. De acordo com Renn, cabem neste espectro perspectivas teóricas tais como a teoria da ação racional, a teoria da mobilização social, a teoria organizacional, a teoria de sistemas, e também as teorias críticas neomarxistas, além da teoria culturalista e do construcionismo (p.67-70, 1992).

A noção de capitalismo desorganizado tem, pelo menos, duas versões. A versão de Lash \& Urry (1987) procura estabelecer a diferença entre o "capitalismo organizado" como um fenômeno nacional e o capitalismo desorganizado como um fenômeno global, resultante do avanço internacional das empresas multinacionais, atuando tanto no plano industrial como no comercial e financeiro através do qual se processa a descaracterização das fronteiras nacionais. A versão da Carl Offe (1989) está construída fundamentalmente sobre a idéia de que, no novo capitalismo, verifica-se a marginalização do mundo do trabalho, posição questionada pelos dois primeiros autores citados. De qualquer modo, as duas versões se combinam 
com a noção de sociedade de risco, marcando uma vertente comum na relação de ambivalência que, em determinado momento, passa a cercar o desenvolvimento tecnológico associado ao crescimento econômico, quando a racionalidade técnico-científica é identificada como elemento de proteção e legitimação da degradação da vida na sociedade contemporânea (Beck, [1998],1986).

Os conceitos de risco e reflexividade que fluem da trama teórica em que se define a nova modernidade, a modernidade reflexiva ou pós-tradicional (Beck, 1986; Giddens, 1991), compõem o centro nervoso, não apenas de uma outra concepção de construção da teoria sociológica, mas da visão de uma sociedade nova à qual a teoria deve adaptar-se.

Neste movimento de reconstrução teórica, uma das variantes que mais impressionou a discussão foi a do deslocamento do vértice paradigmático da ciência do mundo do trabalho, cuja perda de substância ética seria produto do surgimento de uma sociedade na qual dominam os serviços, para o terreno da comunicação. Claus Offe, em seu texto Capitalismo desorganizado, expõe essa idéia, localizando nas "tradições clássicas da sociologia burguesa", no caso, as obras de Marx, Durkheim e Weber, a tendência em tornar o trabalho o fato social principal (cap.5, 1989). A tese de Offe, apesar de colocar lado a lado, como geminadas, concepções do mundo ancoradas em epistemologias contraditórias, como efetivamente são as teorias dos autores "clássicos" nomeados, foi aceita nos meios acadêmicos com surpreendente facilidade.

Esse fato somente pode ser entendido se considerado como parte do grande enredo paradigmático que se armou em torno da Sociologia nos anos 80. O fator decisivo que concorreu para tornar tão palatável as idéias de Offe sobre as raízes históricas do fundamento da Sociologia em torno do trabalho, na verdade, muito mais do que as suas fontes (localizadas na crítica da ontologia de Karl Marx por Jurgen Habermas e também nos estudos de Ralph Dahrendorf sobre o fim da sociedade do trabalho, de André 
Gorz, sobre o fim do proletariado e de Alain Touraine e Daniel Bell sobre a emergência da sociedade pós-industrial), foi a solução, no meu entender, mais artificiosa do que epistemologicamente correta, do deslocamento do núcleo paradigmático da sociologia do processo de trabalho para a esfera do mercado no qual reinaria racionalidade diversa. O surgimento de outros e diferentes tipos de conflitos sociais na sociedade contemporânea teria esvaziado o antigo núcleo dos conflitos, o mundo da fábrica, local preferencial do enfrentamento entre as classes sociais, proprietários e não proprietários. Esse núcleo transmuta-se numa frente unificada que passa a se confrontar, então, com conflitos sociais emergentes, externos ao processo produtivo. A expansão generalizada dos serviços nas sociedades industrializadas e a conseqüente transformação da natureza do trabalho são a chave da mudança radical na estrutura da vida contemporânea.

O livro de Offe, de certo modo, serve como uma fundamentada amostragem da evolução da tendência teórica que passa a alimentar a voga da idéia de uma outra modernidade e, dentro dela, do conceito de sociedade civil alimentada pelas noções de risco e reflexividade, a transformação do mundo do trabalho funcionando como fonte de sensibilização para os custos sociais e ambientais das atividades produtivas de um modo geral e não apenas aos limitados aos locais de trabalho e empresas determinadas.

A discussão em torno do conceito de sociedade civil irá adquirir uma envergadura inusitada nas análises sociológicas, com o debate em torno do socialismo democrático e do eurocomunismo, nos anos 60-70. No que respeita particularmente aos Estados Unidos e ao Reino Unido, o conceito de sociedade civil parece experimentar um revival a partir da publicação da tradução para a língua inglesa, em 1989, do livro de Jurgen Habermas intitulado Mudança estrutural da esfera pública, editado em 1961.

O texto de Habermas parece carregar em si elementos que servem para uma reavaliação do conceito de sociedade civil, na medida em que projeta a questão a partir da ruptura do "velho modelo" que estabelecia 
rígida separação entre esfera pública e privada construída, conforme seus termos, pela sociedade burguesa. Isto é, a decadência da esfera pública "burguesa" ocorreria sob o patrocínio da integração entre o setor público e o setor privado, com o surgimento de um novo espaço político público. Na raiz do texto de Habermas, estão temas que reorientam toda a discussão em torno das transformações tecnológicas, econômicas, sociais, políticas, culturais e ideológicas que passam a caracterizar a crítica e a reconstrução da concepção de modernidade e a revisão dos paradigmas dominantes na Sociologia, de que Offe, antes mencionado, é um exemplo eloqüente.

No que respeita à literatura sociológica anglo-saxã, há uma clara convergência na consideração de que o conceito de capital social, a partir da formulação de James Coleman e dos desenvolvimentos posteriores do conceito através de estudos de outros autores, funciona como fator central na "vitalização" do conceito de sociedade civil, especialmente nos Estados Unidos, onde isso se verifica concomitantemente com a retomada do pensamento de Alexis de Tocqueville sobre os fundamentos da vida democrática do país (ver, como exemplos, as coletâneas de textos editados por Craig Calhoun, Habermas and the public sphere, em 1992, e Cohen \& Arato, Civil society and political theory, em 1994). A correlação entre os dois conceitos parece encontrar na idéia de esfera pública desenvolvida por Habermas, no texto de 1961, o estímulo decisivo para aceitação como instrumento analítico da ordem política e social. Os novos contornos do conceito de sociedade civil representam um redesenho da idéia de esfera pública de Habermas, no sentido de que a sociedade civil não compreende apenas uma esfera pública, fundada na exclusividade do discurso racional, mas é constituída de múltiplas esferas públicas, nas quais se combinam elementos racionais, não-racionais e elementos de contestação (ver a respeito Calhoun, 1992). Trata-se de um modelo emergente de sociedade civil compreendendo uma série de "esferas públicas, comunidades e associações aninhadas umas dentro das outras e também dentro de uma putativa esfera mais ampla de caráter nacional" (Taylor, 1995, apud Jacobs, p.1239, 1996). 
Nesse movimento, no qual à expansão e à reorientação do sistema capitalista se soma a decadência do sistema soviético, ampliando o horizonte para a reflexão científica no terreno das ciências sociais, o ressurgimento da noção de sociedade civil desempenhará papel estratégico no processo de articulação de análises e categorias que circulavam mais ou menos independentemente nos estudos sociológicos ou nos estudos econômicos, ou em suas respectivas áreas adjacentes. É esse papel estratégico que faz com que o conceito assuma, sob determinadas condições, o sentido de uma autêntica colcha de retalhos em que objetivos analíticos se misturam com pretensões de caráter ético, buscando alternativas para superar conflitos em torno de demandas contraditórias por parte de diferentes instituições, associações ou grupos sociais, com vistas à preservação da ordem social. $\mathrm{O}$ fato de representar a síntese entre bem-estar público e privado parece ser a condição da larga circulação do conceito na literatura anglo-saxã (Foley \& Edwards, 1998; Magnuson, 1997) e o fundamento da sua transformação em instrumento de aproximação entre diferentes campos do conhecimento. Com tal tipo de suporte, a segunda fase da construção da sociologia econômica, terá vitalidade jamais conhecida em sua primeira etapa, com Talcott Parsons, Neil Smelser e Wilbert Moore, nos anos 1960, e será através dela que se consolidará a tendência à afirmação da preponderância da sociologia anglo-americana sobre outras correntes do pensamento sociológico (sobre a segunda fase da sociologia econômica, ver Swedberg, 1997 e p.165-6, 1998).

Nos desdobramentos dessa nova fase, serão atualizadas várias noções, já de ampla circulação nos meios intelectuais e científicos, mas que, no interior do discurso da sociologia econômica, ganham outra dimensão e projeção, em especial na esteira da exploração de conceitos como os de sociedade civil e, principalmente, o de capital social, colaborando decisivamente para aprofundar o viés de curto prazo que define a direção principal do desenvolvimento da sociologia americana contemporânea (Elias, 
[1994],1968; [1997],1977; 1987). Na agenda desta sociologia, os fatores primários da organização das proposições teóricas e metodológicas passam a ser enquadrados de acordo com noções totalmente esvaziadas de seu conteúdo histórico e representando determinações emanadas da nova racionalidade tecnológica, tais como globalização, sociedade da informação, do conhecimento, do risco, da modernidade reflexiva, etc. Nessa tessitura teórico-metodológica, os conflitos têm lugar em termos de interesses divergentes, e a dinâmica central da sociedade se resolve através do processo, ou mecanismo de inclusão/exclusão de indivíduos e grupos em relação às diferentes instâncias de convivência, e institucionais, ou situações sociais. É aqui que se define o sentido estratégico do conceito de capital social.

O conceito de capital social, em Coleman, representa assumidamente o desenvolvimento da teoria da troca e a consolidação da teoria da escolha racional dentro da Sociologia. A definição de capital social é dada pela sua função, isto é, a criação de capital humano, e suas fontes correspondem basicamente a expectativas e à confiabilidade nas estruturas sociais, às redes e às informações e ao cumprimento de regras e acolhimento de sanções preestabelecidas pelas estruturas sociais. Sua fungibilidade é praticamente nula, comparativamente ao capital humano e ao capital físico. Isso se deve ao fato de que ele não está localizado nem nos indivíduos nem em fatores físicos do processo produtivo. A substância do capital social, de acordo com Coleman, é o seu sentido propositivo e, nesse caso, é a organização social (sistema de ação ou ator corporativo) que enseja a realização de propósitos que não seriam alcançados de outro modo, a não ser com um custo muito elevado.

A argumentação em torno do tema tem lugar no texto divulgado no suplemento do American Journal of Sociology de 1988 e é desenvolvida no livro Foundations of social theory, em 1990, considerada a obra máxima do autor, na qual são retomados vários textos publicados anteriormente e são reunidos os elementos de demonstração do que constitui, na avaliação do 
autor, a redescoberta das bases da vida em comunidade subseqüente à transformação organizacional revolucionária que marcou a emergência da sociedade contemporânea, a corporação moderna (ou sociedade anônima). Outro documento importante para avaliar esse projeto corresponde à mensagem presidencial apresentada à sessão inaugural da Sociedade Americana de Sociologia, em 1992 (Coleman, 1993), na qual se encontra uma síntese da sua idéia de reconstrução racional da sociedade e o papel da Sociologia nesse processo.

A noção de ator corporativo domina o texto de 1990 e a mensagem aos sociólogos de 1993. Como o texto de Foundations é uma composição que integra textos anteriores, em muitos momentos nos encontramos com a retomada de idéias já expostas, e isso parece colaborar para criar a impressão de pouca clareza no enunciado do conceito. A reiteração de algumas questões, no entanto, também funciona no sentido de favorecer a consolidação de determinados pontos fundamentais da sua teoria. É o caso da definição do ator corporativo como sistema de ação, através da qual fica evidente a pretensão de Coleman de estender a teoria da ação racional a todas as instâncias estruturais da vida coletiva. Tome-se, por exemplo, a caracterização de ator corporativo mínimo: "Uma pessoa natural", diz ele, "comporta dois seres, um ser objeto e um ser atuante, ou principal e agente, em um corpo físico. O ator corporativo mínimo é criado quando principal e agente são duas pessoas diferentes". E prossegue, "com essa estrutura mínima, o principal pode ser um ator corporativo, ou o agente pode ser um ator corporativo, ou ambos podem ser atores corporativos (como quando uma corporação possui outra corporação)". Ator corporativo mais extensamente desenvolvido é o que possui múltiplos "principais" compondo o ser objeto e muitos "agentes" constituindo-se no seres atuantes. "Esta é a forma em que é concebida na sociedade moderna a corporação publicamente possuída". Coleman explica esta ocorrência da seguinte maneira: "Os principais são os múltiplos proprietários, os acionistas da corporação; os 
agentes são todos os empregados da corporação, desde seu gerente colocado no mais elevado grau da hierarquia da corporação até os trabalhadores da produção". A mesma idéia valerá para os sindicatos, cujos membros são os principais dispersos, e os integrantes da direção são os agentes através dos quais são filtradas as demandas, e para o Estado no qual os cidadãos são os principais e os funcionários do governo são os agentes (p.421, 1990).

Muito embora a idéia de ator corporativo se expresse como um sistema presente em diferentes estruturas organizadas da sociedade, praticamente toda a argumentação de Coleman envolvendo a explicação da formação e do desenvolvimento do conceito e de seu núcleo de origem é feita tomando por referência a corporação moderna, em razão de ser esse tipo de organização a que patrocina a radical mudança na ordem legal da sociedade e, conseqüentemente, a mudança da organização social que definirá o rumo da sociedade contemporânea.

A larga exploração que o conceito de capital social irá experimentar nos anos 90 ocorre, significativamente, amputada do seu complemento teórico, o ator corporativo, tal como desenvolvido por Coleman. Se acompanharmos a evolução do uso do conceito de capital social nas ciências sociais através do artigo de Alejandro Portes (p.18, 1998), verificarem os que, nessa época, ou mais precisamente, em 1993, com Robert Putnam, tem início uma reviravolta na exploração do conceito, com a sua fundamentação operada por intermédio da atuação de organizações cívicas, associações de diferentes tipos, comunidades e, inclusive, em alguns casos, cidades e países. Colocando em outros termos, a articulação do conceito de capital social com órgãos representativos da "sociedade civil" é o elemento decisivo para o desabrochar do conceito em diferentes contextos. Este tipo de articulação parece ensejar o modo ideal de contornar o problema institucional que envolvia o conceito de capital social na formulação colemiana, articulado à noção de ator corporativo, tornando-o um conceito assimilável, ou mais palatável, em círculos situados além dos ambientes 
acadêmicos, tais como o Banco Mundial e o Fundo Monetário Internacional, para citar dois exemplos de órgãos vinculados à formulação da política econômico-financeira mundial. Será principalmente com suporte em Coleman, Putnam (1993) e Fukuyama (1995) que o conceito de capital social, caracterizado como nova perspectiva do desenvolvimento, passa a representar elemento basilar nas discussões e estudos levados a efeito por investigadores ligados ao Banco Mundial em torno da problemática da pobreza, e a servir como instrumento de readequação das proposições da instituição sobre o tema do crescimento econômico do sistema periférico (ver Grootaert, 1998, Grootaert e Bastelaer, 2001).

É importante registrar, a esse respeito, o fato de que a contribuição de Pierre Bourdieu sobre o conceito de capital social, anterior às abordagens de Coleman sobre o tema, só é mencionada acidentalmente na série de papers da Social Capital Iniciative, do Banco Mundial, iniciada em 1996, época em que, ao que tudo indica, também começa a circular, no Fundo Monetário Internacional, o conceito de sociedade civil (Dawson e Bhatt, 2001). Este parece ser um dado definitivo da distância que marca as duas contribuições teóricas. Enquanto a preocupação de Bourdieu se dirige fundamentalmente para a construção de um novo patamar teórico de consideração da relação entre o indivíduo e a sociedade, com a finalidade de dar mais consistência histórica às análises da vida em sociedade, Coleman, também operando no campo da relação micro-macro, parecerá mais preocupado com desvencilhar a Sociologia do seu conteúdo histórico para the dar o sentido de um projeto de organização racional da sociedade. A sua contribuição está mais adequada à pretensão de sustentabilidade de programas de desenvolvimento orientados estrategicamente para o fortalecimento de redes e instituições sociais.

As restrições aos argumentos de Coleman em Foundations, atadas em grande proporção, ao tema do ator corporativo e a supostas incongruências da argumentação utilizada para sustentar o conceito (Stinchcombe et 
alii, p.183-262, 1992; Tuomela, 1993 e Lindenberg, 2003) não servem para desqualificar o autor, seja em termos da sua representatividade na sociologia americana, seja em termos do papel que desempenha no momento histórico da reflexão sociológica e as circunstâncias que marcam a etapa de desenvolvimento econômico e político dos Estados Unidos e do seu papel da economia mundial em fins do século 20. A dimensão e o real significado do livro somente podem ser devidamente avaliados quando projetados na perspectiva histórica e, sondadas as possíveis razões que fizeram Coleman trazer de volta à cena sociológica do país, um tema que, por motivos não muito claros, havia sido abandonado depois de ser amplamente explorado pelos sociólogos do pós-guerra. A partir do fim da Segunda Guerra e estendendo-se pelo menos até os anos 60, o debate em torno da questão do controle da propriedade corporativa foi alvo de análises e investigações empíricas por parte de sociólogos que, amparados na obra clássica de Berle e Means (1932), extraíram conclusões positivas sobre a natureza daquele processo, em termos dos efeitos sobre a estratificação social e da repercussão que esses efeitos teriam no aperfeiçoamento da vida democrática do país. O que dá uma significação muito especial aos textos de Coleman a respeito da noção de ator corporativo é precisamente a condição de deixar evidente, a contrário senso da direção dominante no pensamento dos sociólogos que anteriormente se haviam dedicado ao assunto, é que Berle e Means tinham clara noção de que a separação entre propriedade e controle operada nas sociedades anônimas gerava, no interior do movimento de concentração de poder desencadeado, uma distorção nas relações, envolvendo os personagens emergentes na vida econômica e os antigos atores, fatos que tinham repercussão importante na esfera política. A "fissão do átomo da propriedade", ao proporcionar a constituição de grupos de gerentes que atuavam de forma independente, tanto dos acionistas quanto dos proprietários, configurava, deste modo, uma tendência oligárquica que contaminava o sentido positivo da experiência original. As constantes alu- 
sões, em Foundations, ao texto de Robert Michels ([1982], 1914) sobre os partidos políticos, várias vezes mencionado, algumas delas ao lado de referências ao clássico texto de Berle e Means sobre a corporação moderna, são indicativas da preocupação do autor em querer livrar a caracterização do conceito de ator corporativo dos problemas decorrentes da burocratização dos sistemas organizacionais que a progressão econômica acelerada das corporações evidenciava, bem como a necessidade de contornar a possível contaminação de seu projeto de organização racional da sociedade pela "lei de ferro das organizações".

Construção original de Coleman, o conceito de ator corporativo e a articulação de suas raízes teóricas com a trajetória histórica das sociedades anônimas no País repercutiu na reflexão sociológica americana desde, ao que tudo indica, 1974, com a publicação de Power and the structure of society. Nesta época, sua análise encaixa num contexto em que a questão do poder e da responsabilidade social das corporações funciona como epicentro de um debate político que irá ganhar projeção cada vez maior no País. O relativo consenso até então existente na ciência social em torno do sistema político americano, no qual, de acordo com Rick Tilman (1974), a ambigüidade dos escritos de Adolf Berle, co-autor de A propriedade privada na economia moderna, tinham papel importante, é rompido pelo debate entre defensores do pluralismo e do elitismo.

No ano de 1988, quando Coleman apresenta a noção de capital social articulada à noção de ator corporativo, a qual ele desenvolvia desde, pelo menos, a década anterior, e o posterior desdobramento teórico dessa articulação em 1990 e 1993, marca o momento em que as bases institucionais do poder do País estão sendo postas em debate, em que temas como o da cidadania corporativa e a crítica às pressões e ao avanço das tendências tecnoburocráticas das corporações na reestruturação do poder federal americano se entrelaçam num emaranhado de indagações sobre a dinâmica central do processo de globalização e seus efeitos sobre a democracia no 
país e no mundo (ver a propósito, entre outras análises, Melman,1997; Gordon, 1998; Boggs, 1999; Farazmand, 1999; Sklair, 2002; Carrol e Fennema, 2002; Carrol \& Carson, 2003; Skocpol, 2003; Mizruchi, 2004). O projeto político-institucional de Coleman não é apenas parte integrante desse panorama, mas um dos seus componentes fundamentais.

Não é acidental que esse projeto de mudança social orientada, construído no interior de uma obra revestida do sentido de um tratado geral de teoria social, segundo a caracterização de Foundations of social theory por Patrick Baert (p.164, 1998), pareça servir de linha de convergência para um conjunto de questões que circulam em diferentes meios e se refletem na discussão em curso no campo das ciências sociais. O conceito de capital social é peça central na arquitetura da Sociologia do novo milênio e, tal como aparece em Coleman, emana do próprio núcleo do pensamento sociológico americano a concepção de sistema social e a preocupação mais recente com a relação micro-macro (e nessa direção estritamente).De acordo com Coleman, como modelo de troca dentro do sistema de ação social, a idéia de capital social funciona como instrumento conceitual para operar a conjugação de duas vertentes teóricas, descritivas e interpretativas, da ação social, uma, manipulada pela maioria dos sociólogos que entendem a ação social dirigida por normas, regras e obrigações, e outra, pela maioria dos economistas que vêem as ações dos atores como independentes e orientadas para o interesse próprio (S95-S96, 1998). Em certo sentido, assim procedendo, ele tende a transformar o paradigma da ação racional no inter lingua das ciências sociais. Mas, além disso, o que parece decisivo dentro da conjuntura teórica de fins do século 20 e inícios do século 21, é a sua intimidade com a nova teoria do desenvolvimento, refletindo os problemas institucionais da sociedade americana e da nova configuração da divisão internacional do trabalho.

A teoria do desenvolvimento que surge no final dos anos 80, em substituição às diversas versões de tipo estruturalistas até então dominan- 
tes, tem como matriz econômica a racionalidade tecnológica (ver a respeito, entre outros textos: Greif, 1994; Evans, 1996; Hyden, 1997; Nahapiet \& Ghoshal, 1998; Woolcock, 1998; Fine, 1999 e 2001; Woolcock \& Narayan, 2000; Fevre, 2000; Maskell, 2000; Biggart \& Castanias, 2001; Piazza-Georgi, 2002; Routledge \& Amsberg, 2003; Bezemer, Dulleck \& Fritjers, 2004). De um modo geral, a nova teoria é organizada a partir da atuação das grandes empresas transnacionais, e seus elementos centrais de sustentação e justificação social e política estão fundamentados no viés culturalista construído basicamente através de conceitos como os de capital social e de sociedade civil, que funcionam como instrumentos privilegiados para a caracterização das diferenças de desenvolvimento, registradas tanto nos planos regionais, quanto nos nacionais e locais.

Uma das expressões mais representativas dessa direção da teoria do desenvolvimento é a teoria do crescimento econômico endógeno, que incorpora a teoria do capital humano como componente patrocinador da transformação tecnológica. Surgida em meados dos anos 80, essa teoria, desenvolvida por Paul Romer (1986, 1989 e 1990), alcançou grande repercussão nos meios acadêmicos americanos e, nos anos 90, foi integrada, juntamente com a teoria do capital social, ao sofisticado sistema de análises e definições de estratégias de crescimento econômico global gerenciado pelas agências internacionais como a Organização Mundial do Comércio, o Banco Mundial, o Fundo Monetário Internacional e a Organização para a Cooperação e o Desenvolvimento Econômico, etc. Dentre os argumentos principais, sustentados pela teoria de Romer, inspirados principalmente na teoria de Joseph Schumpeter, figuram destacadamente a existência do conflito entre inovação e concorrência perfeita, a necessidade do livre comércio e o investimento nas grandes corporações como via preferencial para a promoção do crescimento econômico através do acesso às novas soluções tecnológicas, explicando pelos mesmos critérios os desníveis existentes nos índices econômicos dos diferentes países. 
Embora não haja elos admitidos explicitamente pelos respectivos autores entre a teoria do crescimento econômico endógeno e a teoria do capital social, não há dúvida de que a inclusão de ambas no mesmo circuito explicativo e propositivo de políticas globais patrocinadas por entidades internacionais se deve à existência de um conjunto de elementos convergentes entre elas, que são também elementos representativos da direção principal da teoria do desenvolvimento que então toma corpo. Assim, por exemplo, as duas teorias têm seu centro nervoso localizado nas grandes corporações modernas e ambas desenvolvem uma percepção crítica da teoria da competição perfeita, percebem a comunicação como forma de economia externa e inserem o processo de organização da informação na avaliação dos custos sociais das transações.

Por outra parte, no caso da teoria do desenvolvimento emergente, é bastante comum encontrarmos as avaliações do processo de desenvolvimento econômico realizadas, tendo como instrumentos analíticos privilegiados, teorias tais como a da escolha racional, da escolha pública, dos jogos, de redes, de agência, de relações micro-macro, capital humano, capital social, confiança, cidadania corporativa, sociedade civil, governo corporativo, institucionalismo, comunitarismo, etc., todas orientadas pela perspectiva do curto termo. Tal conjugação de campos teóricos e conceituais também informa, explica e justifica as políticas econômicas e sociais globais, regionais, nacionais e locais sob a égide de organismos internacionais, tendo como pólo de mobilização o conceito de capital social. É essa condição que dá a tal conceito a condição de "elo perdido" da teoria do desenvolvimento e de "cola que mantém as sociedades unidas", para mencionar as metáforas mais sugestivas mencionadas em estudos levados a efeito por integrantes do staff do Banco Mundial, como lembra Ben Fine (p.158, 2001).

Quando se realiza a aproximação entre a teoria de James Coleman à teoria do crescimento de Paul Romer, configura-se de modo bastante claro o papel do conceito de capital social como uma espécie de microssistema 
que funciona como ponto de equilíbrio teórico de um processo que tem na inovação tecnológica a sua dinâmica fundamental e, no sistema de informações controlado pelas grandes empresas, o meio decisivo de definição de estratégias para a garantia da reprodução dos negócios, tudo justificado pelas "imperfeições" do mercado.

Keynes que, com muita razão, é lembrado como um dos maiores representantes da teoria social do século 20 (Lemert, 1999), parece enunciar a estratégia principal da teoria do desenvolvimento que se definiu no fim do século, após o suposto esgotamento da sua filosofia econômica. Dizia ele, em 1936, na sua Teoria Ceral, que os economistas jamais haviam tratado devidamente o tema do "estado de confiança", tratando dele apenas de modo ocasional e genericamente. Não era este o caso dos "homens práti$\cos ^{\prime \prime}$ que faziam desta questão objeto de permanente interesse e preocupação (p.136, [1943], 1936). Como lembra Jeffrey Alexander (p.150, 1995), Keynes, nessa oportunidade, sugeria que, diante da incapacidade objetiva de conhecer o futuro além das projeções de tipo probabilístico, abria-se definitivamente a porta para a motivação irracional e para o conceito de confiança.

Essas observações de Keynes apontam para o âmago da teoria do desenvolvimento, forjada para explicar e justificar o movimento econômico contemporâneo e suas repercussões no plano político. Como microssistema de equilíbrio das relações sociais, o conceito de capital social aparece perfeitamente enquadrado dentro desse cenário como seu campo principal. Dentre as múltiplas caracterizações que a noção apresenta, especialmente dentro da Sociologia produzida nos Estados Unidos ou dela derivada, duas delas definem, no meu entender, a sua substância efetiva. Na realidade, uma dupla substância. Uma, de caráter subjetivo e outra, de caráter objetivo. Desde o ponto de vista subjetivo, a substância comum é a confiança, que alguns entendem como elemento central pela sua condição como fator de convergência e aglutinação conceitual. A substância objetiva, comum a todas as abordagens do conceito de capital social é, sem dúvida, a 
questão da informação. Assumida como fator desencadeante e animador de todo o processo de construção de relações sociais estáveis, a informação prefigura-se como elo de articulação entre o processo de racionalização técnica induzido pelo sistema produtivo e o esvaziamento ideológico dos conflitos sociais, reduzidos a diferenças culturais e grupais.

Como microssistema de informação, o conceito de capital social surge, nos últimos anos, como elemento-chave na configuração do paradigma da nova economia: o processo de destruição criativa (conforme Greenspan, 1999, Aghion e Howitt, 1992; Nakamura, 2000; Halal e Taylor, 2002; Grennes, 2003; Alcouffe e Kuhn, 2004). Desse modo, ele irá naturalmente fazer parte do contexto em que está imerso o processo que Ulrich Beck (p.12, 1997) classificou como a "reinvenção da sociedade industrial", isto é, o processo de "modernização reflexiva", ou a "autodestruição criativa de uma era", e que Giddens (cap. 2, 1997), por seu turno, caracterizou como movimento de abandono, desincorporação e problematização da tradição (ou genericamente "destradicionalização"), compreendido na modernidade emergente.

De outra parte, o conceito de capital social, percebido fundamentalmente como microssistema mobilizador da confiança, corresponde à contrapartida subjetiva do processo de modernização, vinculando-se às noções de risco e reflexividade (Coleman, cap.5, 1990; Giddens, op.cit. cap. 1 e 2) e incorporando-se às obrigações e sentimentos morais abrigados no núcleo cultural que subsidia a prosperidade na sociedade pós-industrial (Fukuyama, parte I, 1996).

Nesta dupla substância, reside o motivo da larga penetração do conceito de capital social no debate sobre políticas públicas, em praticamente todos os níveis e instâncias de verificação. É a sua propriedade de unificação de discursos que lhe garante a função estratégica adquirida na nova teoria do desenvolvimento econômico e na definição dos rumos da Sociologia e das ciências sociais no novo século. 
É preciso colocar o conceito de capital social na perspectiva histórica da terceira revolução tecnológica, para que o seu sentido real e efetivo se torne claro. O conceito de capital social, tal como definido originalmente por Coleman, isto é, pela sua função na criação de capital humano, é um produto típico da assim chamada "sociedade do conhecimento" ou "sociedade da informação". Se, para os economistas, como sugeriu Ben Fine (op.cit: 97), a noção de capital social representa um modo não mercantil de explicar as imperfeições do mercado, do ponto de vista da concepção de desenvolvimento econômico e social construída a partir da mudança tecnológica, isto é, desde o ponto de vista da prevalência de uma racionalidade essencialmente técnica como elemento central da mudança social, ele é o complemento epistemológico do conceito de capital humano. E, neste sentido, funciona como fator decisivo do metabolismo sociocultural e político de aceitação, não só das imperfeições do mercado, mas da inevitabilidade dos fatos econômicos.

Evidência concreta dessa condição é a correspondência histórica entre o surgimento e difusão do conceito e o aprofundamento, nas últimas décadas do século 20, dos debates e das disputas políticas e teóricas em torno da natureza e do escopo do direito da propriedade industrial, assentados precisamente sobre o processo de expansão das novas tecnologias da informação e da comunicação e a repercussão que provocam em torno da necessidade de redimensionamento do direito de propriedade intelectual.

James Coleman oferece pistas bastante importantes desta ocorrência em vários momentos de Foundations. Dentre as situações examinadas por ele, uma das mais ilustrativas é o caso da caracterização da inalienabilidade prática do capital social, quando comparado a outros bens divisíveis e objeto de propriedade privada, como, por exemplo, o capital físico e o capital humano, e do sentido fundamentalmente social que os envolve como atributo da estrutura de relação em que o indivíduo está imerso (cap.12). 
Também sugestivo é o capítulo dedicado ao exame do ator corporativo como um sistema de ação, no qual se destaca a análise dos efeitos derivados do desenvolvimento da tecnologia informática na erosão do direito de propriedade, sobre as idéias e as inovações criadas no seio das atividades patrocinadas pelas corporações (cap.16). Isso porque as novas estruturas organizacionais que surgem com o desenvolvimento da computação promovem a facilitação do "transporte de idéias" de um setor a outro da atividade industrial, ensejam a autonomia organizativa de empresas (e de trabaIhadores), estimulam ainda mais fortemente a articulação entre pesquisas e pesquisadores sediados em instituições universitárias e empresas, etc.. Induzidas pela nova tecnologia, portanto, as estruturas organizacionais das empresas, de um modo geral, tendem a consagrar uma nova modalidade de alocação de direitos de propriedade para as idéias e inovações engendradas em atividades desenvolvidas dentro das organizações, procurando resguardar os direitos dos "agentes corporativos" envolvidos, dando forma ao processo de difusão ampla do conceito de propriedade compartilhada entre a corporação e seus empregados.

O fenômeno identificado como "desindustrialização", ou "trânsito para a economia da informação", ou ainda, "terciarização" que, no fundo, definem o que se convencionou entender como a emergência da "sociedade do conhecimento" ou "sociedade da informação" e cujo registro se torna insistente na literatura econômica dos países avançados, particularmente na dos Estados Unidos, no início da década de 1970, configurando o momento e o entorno em que emerge o conceito de capital social. A idéia de capital social definida pela função precípua de criação de capital humano corresponde, para utilizar os termos de um economista americano, ao "imperativo de considerar os humanos como mercadorias", ou, utilizando a expressão de Theodore Schultz, considerá-los como "máquinas de capital humano" (Adams, p.627, 1982). Dentro desta lógica, o conceito de capital social serve como instrumento para identificação da substância coletiva do 
conhecimento embutido no capital humano e funciona, portanto, de modo a caracterizar o campo do que é "comum", ou seja, do que é de domínio público e que necessita de uma organização suficientemente ágil e apta para controlar a sua aplicação e, assim, torná-lo útil para "toda" a sociedade.

A assimilação, pelas ciências sociais, dessa teoria da origem social do conhecimento do trabalhador que, efetivamente, num determinado momento histórico, corresponde à necessidade de socialização controlada deste conhecimento, é uma etapa do processo de readequação do conceito de propriedade diante dos rumos definidos pelo desenvolvimento e expansão da tecnologia, bem como as condições emergentes no processo competitivo. Neste sentido, os conceitos de capital social e de capital humano fazem parte do conjunto de situações que, num determinado momento, obrigam a lógica empresarial a desenvolver um intenso esforço para estender a planificação dos custos salariais, muito além da esfera de negociação de contratos, para invadir a própria organização da vida do trabalhador. Esse esforço, travestido em lógica do mercado, é o que está por trás da tentativa de integração planificada do circuito inovação-produção-consumo que, em fins dos anos 1970, apareceria traduzido na idéia de prosumer, desenvolvida por Alvin Toffler, como representando a ruptura do divórcio entre produtor e consumidor. Tendência que logo se consagraria nos círculos acadêmicos relacionados à teoria da organização de empresas, através da noção de mass customization (ou "customização maciça", tal como a expressão vem traduzida para o português no livro de Joseph Pine II, Personalizando produtos e serviços, de 1994).

Esse conceito, que começa a circular por volta de 1987, através de Stan Davis nos Estados Unidos, é apresentado como uma visão pretensamente holística da vida econômica e que tem seu objetivo orientado para a conversão das formas e dos modelos de consumo em fatores determinantes dos modelos e formas do processo de produção, utilizando como justificativa deste propósito os efeitos provocados na vida em geral 
pelas inovações induzidas pelas novas técnicas de comunicação e de informação (Boynton, Victor e Pine II,1993; Davis, [1996], 1987, 1994, 1998; Davis e Meyer, 1997, 1999, Cox e Alm 1998, Pine II, 1994). Ele se enquadra na perspectiva da verificação de uma nova etapa de evolução das grandes corporações multinacionais, em face de transformações que teriam ocorrido no mercado, isto é, de um mercado que passaria de vendedor a comprador, impondo a inovação e a exclusividade como novas características da demanda, segundo a análise de Bolwijn e Kumpe (1990).

É dentro deste cenário, que o campo conceitual da teoria social desenvolvida em torno da "intangibilidade" do trabalho seria enriquecido com outra noção, a de capital intelectual, que passa a circular em textos jornalísticos de Thomas Stewart de 1991 e 1992, e, em 1997, é transposto para o seu livro Intellectual capital: the new wealth of organizations. Este conceito experimenta grande projeção na teoria das organizações, tendo como preocupação central o exame do processo de manipulação do conhecimento nas corporações (ver, entre outros, Liebeskind, 1996; Spender, 1996; Spender e Grant, 1996).

De uma maneira geral, a imprecisão cerca a noção de capital intelectual. O que parece ser mais consistente na sua análise são três aspectos: em primeiro lugar, a sua vinculação à chamada nova economia; em segundo lugar, vem o seu campo de atuação, a esfera da organização empresarial, quando suas origens são ligadas ao pensamento de Alfred Marshal e à afirmação de que o conhecimento é o seu mais poderoso engenho da organização. Em terceiro, mas não menos importante, vem o seu caráter de noção complementar ao conceito de capital humano (ver a propósito desses três pontos: Saint-Onge, 1996; Nahapiet e Ghoshal, 1998; Ullrich, 1998; Edvinsson, 2000; Nerdrum, 2001).

Fica evidente nos textos de diferentes autores que examinam a emergência e o conteúdo do conceito de capital intelectual, a idéia de que a organização e, particularmente, um determinado tipo de organização, a 
corporação, é o contexto institucional por excelência para o seu desenvolvimento. Fica também perfeitamente clara, nas exposições em torno do tema, a condição que o conceito de capital intelectual assume como elemento estratégico da sobrevivência das empresas dentro de um contexto altamente competitivo, que é traduzido pela noção de mass customization, representativa de uma transformação decisiva que teria ocorrido no mercado capitalista nos últimos tempos.

De um modo geral, fica omisso na consideração do surgimento do conceito de capital intelectual e de sua célere expansão no circuito ligado aos estudos sobre as organizações empresariais a respeito dos efeitos que as novas tecnologias da informação e da comunicação exercem sobre elas, fatos intervenientes nas economias nacionais, derivados de transformações na divisão internacional do trabalho, os quais são decisivos, no sentido de provocar um movimento de reordenamento das relações de poder e do direito de propriedade.

Uma observação importante a este respeito vem incluída na análise de Lester Thurow (2000) referente à ação das novas tecnologias no processo de reorganização da economia mundial. Thurow identificou dois momentos do processo de globalização. Numa primeira fase, ou onda, subseqüente à Segunda Guerra Mundial, o processo de integração da economia mundial fora dirigido por dois grandes blocos de nações, articulados em torno da Guerra Fria. Nessa etapa, as empresas, ainda muito dependentes dos seus países de origem, tendem a expandir suas fronteiras transnacionais. Numa segunda fase do processo de globalização, iniciada por volta dos anos 1980 e acelerando-se nos anos 1990 com o avanço da economia chinesa e o desmantelamento da União Soviética, o desenvolvimento tecnológico serviria como instrumento para a ampliação da ação empresarial, condicionando o comportamento dos países de origem e daqueles em que se instalam, a seus interesses econômicos e financeiros. Seria nesse contexto que a questão da propriedade intelectual se apresentaria como principal contencioso do sistema econômico internacional. 
Significativamente, com o aquecimento da discussão a respeito dos direitos de propriedade intelectual, o tema das enclosure laws inglesas viria novamente à tona. O próprio Lester Thurow (1997), comentando a importância da informação e da tecnologia da informação no movimento da globalização, lembrou a importância que elas tiveram no desencadeamento da Revolução Industrial e acentuou a necessidade de se examinar com muito cuidado a questão dos direitos de propriedade intelectual a fim de evitar que esses direitos se transformassem numa grande confusão, em razão de interesses de grupos econômicos poderosos.

Um dos aspectos mais sugestivos e importantes do debate que se desenvolve a partir de então, em torno do direito de propriedade intelectual ante as transformações tecnológicas em curso, tem por referência a análise das já mencionadas leis que regularam o uso das terras produtivas na Inglaterra, a partir do século 15, dizendo respeito à caracterização do domínio comum como domínio público e das suas relações com o domínio privado. Este é o caso de análises realizadas por James Boyle (2002 e 2003), no sentido de caracterizar as tentativas de regulamentação da propriedade intelectual que então começavam a se definir como um segundo momento histórico da ocorrência das enclosure laws, tendo agora a privatização da propriedade intelectual como alvo preferido. Isto é, o "cercamento dos intangíveis comuns da mente", na formulação de Boyle. A abordagem deste autor apreende a notável expansão dos direitos de propriedade intelectual nos últimos tempos que, indo desde o registro de patentes de conhecimentos científicos, de novos métodos de produção e de realização de negócios, de sistemas digitalizados, etc., chegam a ameaçar as antigas fronteiras da propriedade intelectual. Seu depoimento é eloqüente:

Os limites segundo os quais os direitos de propriedade intelectual eram exceção e não a norma e de que as idéias e os fatos deviam permanecer em domínio público estão sob ataque (...) O 'comum' de fatos e idéias 
está sendo cercado. O sistema de patentes está sendo estendido para cobrir questões que há vinte anos atrás todos os especialistas no assunto concordavam em serem impatenteáveis (...). Na nova visão da propriedade intelectual (...) a propriedade deve ser estendida por toda parte - mais é melhor (p. 38-40, 2003).

As similaridades entre o primeiro movimento das enclosure laws e o processo que o autor entende como sendo um segundo movimento de mesmo tipo, acentuam-se na medida em que a oposição às tentativas de expandir o processo de privatização das idéias é caracterizada como economicamente inconseqüente, e os beneficiários sustentam que a expansão do direito de propriedade é necessária para garantir o progresso. Mas, se existem similaridades entre os dois movimentos, existem também as dissimilaridades. Contrastando com o cercamento de terras produtivas no qual geralmente o uso da terra para determinados fins impedia a sua exploração para outros, Boyle aponta duas das direções em que essa dissimilaridade pode ser identificada. Os intangíveis da mente podem ser explorados simultaneamente por muitos e não se esgotam com o uso. Isso, por uma parte. Por outra, observa-se que o excesso de proteção da propriedade intelectual também cria uma série de problemas para o processo de inovação industrial, aumentando custos e reduzindo o acesso a recursos necessários para a elaboração de novos produtos, além de criar embaraços para a comunicação e colaboração entre setores de pesquisa científica (Boyle, op. cit.: 40-3; sobre o assunto ver também: National Research Council, 2000; David, 2001, Hansson, Husted e Vestergaard, 2005).

Essas observações de Boyle alertam para o sentido menos aparente da idéia de mass customization como suposta nova matriz da vida econômica. Todo discurso que envolve esse conceito nos textos de teoria da organização empresarial está montado sobre o imperativo da inovação tecnológica como fórmula para sustentação da competitividade das empresas diante de um mercado altamente volátil. Mercado que é fundamentalmente "com- 
prador". O que define a mudança da matriz "produto-processo" de "estável" para "dinâmico", de acordo com a teoria, é precisamente a condição de a invenção ser agilizada por processos inovadores e combinada com a constante busca da variedade de produtos (Boynton, Victor e Pine II, 1993). Esta é uma razão bastante forte para que a questão da propriedade intelectual e a disputa por patentes ganhe tamanho vigor nas últimas décadas do século 20. Certamente não é a única razão nem a mais importante.

Os suportes para o questionamento da legitimidade da apropriação das invenções descobertas e as inovações realizadas no processo de produção industrial por parte das empresas podem ser encontrados tanto nas observações sobre a divisão do trabalho de Adam Smith (Smith, v.l, 1981), quanto nas de Karl Marx (v. 1, seção IV, 1946), por exemplo. Os mesmos argumentos destes clássicos da economia política podem ser usados para jogar no desvão das fórmulas mercadológicas da tecnoburocracia a idéia de que as inovações são impostas pela demanda de produtos. O que fica evidenciado na análise das condições em que se operam as inovações de um modo geral é a necessidade de implementação dos sistemas de controle que as empresas exercem sobre os "intangíveis da mente" para não perderem o poder sobre o chief-engine da produção (Freeman, 1994, Uzunidis e Laperche, 1997; Alter, 2002).

Se os defensores do livre mercado, no século 19, eram vigorosamente contra o direito de propriedade intelectual por entenderem que se tratava de um resquício de monopólio feudal, observa Perelman (2003a), hoje o direito de propriedade intelectual transforma radicalmente a natureza da competição. Diante da nova situação do mercado, o controle das empresas sobre os direitos de propriedade intelectual, diferentemente do correspondente ao direito de propriedade sobre coisas materiais, é um controle que se exerce diretamente sobre as pessoas e assume uma feição muito mais intrusiva.

As condições de verificação deste controle se revestem de características peculiares. Perelman (2003a e 2003b) desenha, a partir da leitura de 
Marx, um quadro bastante sugestivo para projetar essas peculiaridades que, em determinado momento, funcionam no sentido de tornar a questão da propriedade intelectual o elemento decisivo nas mudanças impulsionadas pela revolução cibernética na divisão internacional do trabalho. Trata-se da noção de trabalho universal que Marx aborda em determinados momentos de seus escritos para acentuar o fato de que as idéias e descobertas são sempre produtos coletivos e não, produtos de uma única pessoa ou organização. Um desses textos é particularmente chamativo. É o texto em que ele se refere ao fato de o capital fixo servir para mostrar a transformação do conhecimento em força produtiva imediata, evidenciando o ponto em que "a vida social mesmo está submetida aos controles do general intellect e remodeladas conforme o mesmo" (Marx, v.2, p.230, 1982). Perelman entende que Marx jamais teria visto neste fato a raiz da superação do sistema capitalista, mas certamente alertava para uma importante transformação na visão tradicional do sistema de competição mercantil. Desenhava um novo panorama do mercado, diante do qual "os capitalistas não podiam mais simular que estavam desempenhando funções sociais ao perseguir a acumulação através da direção dos trabalhadores por mais tempo ou mais duramente ou mesmo organizando-os de modo mais eficiente" (p. 306, 2003b).

A disputa em torno da propriedade intelectual permaneceria envolta numa nebulosa de ambigüidades, enquanto o processo de apropriação do conhecimento alheio permanecesse realizado praticamente sem custos para as empresas. Isto é, enquanto o "trabalho universal" não tivesse grande significação. No entanto, em dois momentos, percebeu-se que as coisas estavam mudando, observa Perelman. Um primeiro momento de pressão sobre a propriedade intelectual se registraria na ocasião da grande crise da economia mundial em fins do século 19, quando os economistas se teriam apercebido da importância da propriedade intelectual como elemento estratégico para tentar reverter o curso dos acontecimentos e evitar a catástrofe econômica. Um segundo momento começaria, nos Estados Unidos, 
na década de 1960, quando, para contornar a estagnação que envolvia a economia do país, a atenção voltava-se novamente para os direitos sobre a propriedade intelectual. Então, "quando muitas das indústrias da linha antiga não podiam mais competir efetivamente nos mercados mundiais, as taxas de exportação sobre propriedades intelectuais e copyrights voaram" (p. 307, 2003b).

Esses dois momentos correspondem a etapas bem caracterizadas do desenvolvimento de uma concepção das relações entre capital e trabalho, tendo como núcleo de sustentação teórica a articulação entre o mundo empresarial e as ciências sociais. A passagem do século 19 para o século 20 foi marcada, na sociedade americana, pela necessidade de aumento da produtividade industrial, associada a um esforço de valorização do trabalho e do trabalhador, com diversas experiências destinadas a aumentar o controle sobre as organizações, tanto empresariais quanto de trabalhadores, sendo postas em prática a partir daquela base. O segundo momento é balizado por transformações estruturais na economia americana, derivadas do desenvolvimento tecnológico. Essas transformações são observadas, inicialmente, na agricultura. A partir dos anos 1930 e acentuando-se nas décadas seguintes, é identificada uma revolução técnica no setor primário da economia, que se manifesta através dos novos desenhos de máquinas agrícolas e do incremento comercial e de capitalização das fazendas (Oehmke e Schimmelpfennig, 2004). Nas décadas seguintes, o incremento tecnológico no processo industrial dá margem à migração de grandes contingentes de trabalhadores para o setor de serviços, configurando o fenômeno da "desindustrialização" que, de fato, correspondeu a uma ampla reestruturação das atividades econômicas dos países desenvolvidos em geral, mas cuja incidência na sociedade americana foi mais aguda e notável. Esse é o contexto em que se define com maior precisão a aproximação entre as teorias sociológicas e as teorias da organização empresarial, movimento intelectual expresso principalmente através das duas etapas de consolidação da sociologia econômica. 
Entre os instrumentos formativos desta arquitetura teórica, muito distante da solução marxiana do "trabalho universal", estão compreendidos os conceitos de capital humano, capital social e capital intelectual que, no conjunto, pretendem traduzir a natureza nova do capital, gerada no útero da estrutura que teria rompido com a concepção clássica de propriedade, a corporação. Ao invés da dialética, o que fundamenta e ornamenta essa construção teórica é a concepção de desenvolvimento econômico inspirada em Schumpeter, para quem, toda a lógica deriva do modelo de decisão econômica (p.122-123, 1996).

No exame da matriz lógica que orienta a elaboração da teoria social dos capitais intangíveis, a identificação do caráter complementar do conceito de capital intelectual em relação ao capital humano, aparentemente nada mais é do que a reafirmação da função do capital social na criação do capital humano. A análise do contexto em que essa função opera, entretanto, permite vislumbrar uma diferença fundamental entre o capital social e os outros capitais intangíveis. Como elemento gerador do capital humano e do capital intelectual, o capital social é a expressão do que é comum não apenas a todos os trabalhadores, mas é comum a todos os indivíduos de um modo geral e não pertencente a nenhum deles em particular. O capital social tem valor de uso, mas não tem valor de troca, dizia James Coleman. Ele não é propriedade de ninguém. Não somente é comum, mas é público. O mesmo não se verifica com o capital humano que é, dentro dessa linha de argumentação, a substância universal da inteligência, de trabalhadores e não trabalhadores, e com o capital intelectual, que é a matéria prima da inovação e ativado em circunstâncias muito especiais. Enquanto o capital humano representa o conhecimento e a experiência do indivíduo e tem valor de uso e valor de troca, e, portanto não é público, o capital intelectual somente se define como tal no interior da corporação, como uma "vantagem organizacional" da corporação e, conseqüentemente, algo 
que é "comum" enquanto apropriado pela corporação em nome da "comunidade corporativa" (corporate community), mas não é público.

Das soluções construídas pela teoria social para caracterizar o mundo do trabalho como uma extensão do mundo do capital, o capital social é a única forma do capital intangível, que permanece relativamente infungível e impermutável. Nas diferentes versões da formulação do conceito, em Coleman, em Putnam ou em Fukuyama, a sua característica dominante é a condição de ente não maculado por interesses estranhos aos dos grupos envolvidos na sua criação. Ele é um produto natural do sistema social, ou da estrutura social que envolve os indivíduos. No interior dos sistemas sociais definem-se as normas da convivência humana que irão constituir-se em capital social desses indivíduos. Daí deriva o seu caráter de comum e público. É desse modo que ele atua como instrumento da transformação do trabalho universal em capital intelectual, anunciando o seu cercamento preventivo e encaminhando o processo de legitimação da privatização do conhecimento posto em prática pelas corporações.

\section{Referências}

ADAMS, John. The new american economic revolution: down capital and growth, up technology and institutions. Journal of Economic Issues, v. xvi, 2, p.621-628, june 1982.

AGHION, Philippe e HOWITT, Peter. A model of growth through creative destruction. Econometrica, v.60, n. 2, p.323-351, 1992.

ALCOUFFE, Alain e KUHN, Thomas. Schumpeterian endogenous growth theory and evolutionary economics. Journal of Evolucionary Economics, Heidelberg: vol. 14, n. 2, p.223-236, 2004.

ALEXANDER, Jeffrey. Fin de siécle social theory. Relativism, reduction, and the problem of reason. London, New York, Verso, 1995. 
ALTER, Norbert. Les innovateurs du quotidien. L'innovation dans les enterprises. Futuribles. Analyse et Prospective, janvier, n. 271, p.5-23, 2002.

ARRIGHI, Giovanni. O longo século XX. (Trad. Vera Ribeiro) Rio de Janeiro, Contraponto; São Paulo, UNESP, (1996), 1994.

BAERT, Patrick. Social theory in the twentieth century. New York: New York University Press, 1998.

BECK, Ulrich. A reinvenção da política: rumo a uma teoria da modernização reflexiva. In: BECK, Ulrich, GIDDENS, Anthony e LASH, Scott. Modernização reflexiva. Política, tradição e estética na ordem social moderna. (Trad. Magda Lopes) São Paulo, UNESP, p.11-71, (1997), 1995.

BECK, Ulrich. La sociedad del riesgo. Hacia una nueva modernidad. (Trad.Jorge Navarro, Daniel Jiménez, Maria Rosa Borras), Barcelona: Ed. Paidos, (1998), 1986.

BERLE Jr., Adolf A. \& MEANS, Gardiner C. A propriedade privada na economia moderna. Rio de Janeiro, Ed. Ipanema Ltda, (1957), 1932.

BEZEMER, Dirk J., Dulleck, Uwe \& Fritjers, Paul. Social capital, creative destruction and economic growth. Department of Economics, University of Viena, working paper n. 0406, p.30, april 2004.

BIGGART, Nicole W. \& CASTANIAS, Richard. Collateralized social relations. The social economic calculation. American Journal of Economics and Sociology, vol. 60, n. 2 , p.471-500, april 2002.

BOGGS, Carl. The end of politics: corporate power and the decline of the public sphere. New York: The Guilford Press, 1999.

BOLWIJN, P. T. e KUMPE, T. Manufacturing in the 1990's - Productivity, flexibility and innovation. Long Range Planning, vol. 23, n.4, p. 44-57, 1990.

BOYLE, James. Fencing off ideais: enclosure and the disappearance of the public domain. Daedalus. Journal of the American Academy of Arts and Sciences, p.1325, spring 2002.

BOYLE, James. The second enclosure movement and de construction of public domain. Law Contemporary Problems, 66, 1/2, p.33-74, winter/spring 2003. 
BOYNTON, Andrew C., VICTOR, Bart, PINE, B. Joseph II . New competitive strategies: challenges to organizations and information technology. IBM Systems Journal, vol. 32 n. 1, p.40-64, 1993.

BURAWOY, Michael. A sociology for the second great transformation. Annual Review of Sociology, 26, p.693-5, 2000.

CALHOUN, Craig. Habermas and de public sphere. Cambridge, Mass., MIT Press, ed.1992. CAMIC, Charles e GROSS, Neil. Contemporary developments in sociologica theory: current projects and conditions of possibility. Annual Review of Sociology, 24, p.453-76, 1998.

CARROL, William K. \& FENNEMA, Meindert. Is there a transnational business community? International Sociology, vol 17 (3), p.393-419, sept 2002.

CARROL, William K. \& CARSON, Colin. The network of global corporations and elite policy groups: a structure for transnational capitalist class formation? Global Networks 3, 1, p. 29-57, 2003.

COHEN, Jean L. and ARATO, Andrew. Civil society and political theory. Cambridge: Mass., MIT Press, ed.1994.

COLEMAN, James S. Power and the structure of society. New York: Norton and Company Inc, 1974.

COLEMAN, James. Social capital in the creation of human capital. American Sociological Review, vol. 94, supplement, S95-S120, 1988.

COLEMAN, James S. Foundations of social theory. Cambridge, Harvard University Press, 1990.

COLEMAN, James S. The rational reconstruction of society. 1992 Presidential Address. American Sociological Review, 58,1, pp.1-15, feb. 1993.

COLLINS, Randall . Is 1980s sociology in the doldrums? American Journal of Sociology, 91, 6, p.1336-55, may 1986.

COLLINS, Randall. Sociology: proscience or antiscience. American Sociological Review, vol. 54, p.124-139, February 1989.

COX, Michael W. \& ALM, Richard. The right stuff: America's move to mass customization. Economic Review - Federal Reserve Bank of Dallas, Supplement: 3-26, 1988. 
DAVID, Paul A. Will building good fences really make good neighbours in science? Stanford. Stanford Institute for Economic Policy Research, SIEPR Discussion Paper, p.33, 2001.

DAVIS, Stan. Future perfect. Boston MA: Addison-Wesley, (1996), 1987.

DAVIS, Stan. Introdução. PINE II, B. Joseph. Personalizando Produtos e Serviços. Customização maciça. São Paulo: Makron Books, XIX-XXII, 1994.

DAVIS, Stan. Enterview. Techniques, Alexandria. Sept, 73, p.24-25, sept 1998.

DAVIS, Stan \& MEYER, Christopher. "An economy turned on is head: Why you must be "knowledge-based" to compete in today's world (and what that means)". Strategy \& Leadership, Chicago: 25 (6), p.16-19, 1997.

DAVIS, Stan \& MEYER, Christopher. Blur. A Velocidade da Mudança na Economia Integrada. Rio de Janeiro: Campus, 1999.

DAWSON, Thomas C. e BHATT, Gita. The IMF and civil society organizations: striking balance. IMF Policy Discussions Paper, p.29, September 2001.

EDVINSSON, Leif. Some perspectives on intangibles and intellectual capital 2000. Journal of Intellectual Capital, vol. 1. n. 1, pp.12-16, 2000.

ELIAS, Norbert. Introduccion (p.9-46). El processo de la civilizacion. (Trad. Ramon Garcia Cotarelo), México: Fondo de Cultura Económica, (1994), 1968.

ELIAS, Norbert. Towards a theory of social process: a translation. The British Journal of Sociology, v. 48 n.3, p.355-383, (September 1997), 1977.

ELIAS, Norbert (1987). The retreat of sociologists into the present. Theory, Culture \& Society, 4 (2-3): 223-247, 1987.

EVANS, Peter. Development strategies across public-private divide (Introduction). World Development, vol 24. n. 6, p.1033-1037, 1996.

FARAZMAND, Ali (1999). Globalization and public administration. Public Administration Review, 59, 6, p. 509-522, Nov/dec 1999.

FEVRE, Ralph. Socializing social capital: the transition to work, and economic development. In: BARON, Stephen, FIELD, John \& SCHULLER, Tom. Social capital. Critical Perpectives. Oxford: Oxford University Press, p.94-110, 2000. 
FINE, Ben. The developmental state is dead - Long live social capital? Development and Change, vol 30, p.1-19, 1999.

FINE, Ben. Social capital versus social theory. London: Routledge. P.293, 2001.

FOLEY, Michael W. and EDWARDS, Bob. Beyond Tocqueville: Civil society and social capital in comparative perspectives. American Behavioral Scientist, v. 41, 1, p.5-20, 1998.

FREEMAN, Chris. The economics of technical change. Cambridge Journal of Economics, 18, n. 5, p.463-514, October 1994.

FUKUYAMA, Francis. Confiança. As virtudes sociais e a criação da properidade. Trad. Alberto Lopes. Rio de Janeiro: Rocco, 1996.

GIDDENS, Anthony. Social theory and modern sociology. Stanford, Stanford California Press, 1987.

GIDDENS, Anthony. As conseqüências da modernidade. (Trad. Raul Fiker). São Paulo: UNESP, (1991), 1990.

GIDDENS, Anthony. A vida em uma sociedade pós-tradicional. In BECK, Ulrich, 1997.

GIDDENS, Anthony e LASH, Scott. Modernização reflexiva. Política, tradição e estética na ordem social moderna. Trad. Magda Lopes. São Paulo: UNESP, p.73133, 1997.

GIDDENS, Anthony. A Terceira Via. Reflexões sobre o Impasse Político Atual e o Futuro da Social-Democracia. Rio de Janeiro/São Paulo: Record, 1999.

GIDDENS, Anthony. The Third Way and its Critics. Cambridge: Polity Press, 2000.

GORDON, Colin. Why no corporatism in the United States? Business disorganization and its consequences. Business and Economic History, vol. 27, n. 1, p.29-46, 1998.

GREENSPAN, Alain (1999). Commencement address. Harvard University, Cambridge, Massachusetts, http://www.federalreserve.gov/boarddocs/speeches/ 1999/199906102.htm, June 10.

GREIF, Avner. Cultural beliefs and the organization of society: A historical and theoretical reflection on colletivist and individualist societies. Journal of Political Economy, vol 102, n. 5, p.912-950, oct. 1994. 
GRENNES, Thomas. Creative destruction and globalization. Cato Journal, v. 22, n. 3, p.543-558, winter 2003.

GROOTAERT, Christiaan. Social capital: the missing link. Social Capital Iniciative. The World Bank, /working Paper n. 3: www.worldbank.org/socialdevelopment, 1998.

GROOTAERT, Christiaan \& BASTELAER, Thierry van. Understanding and measuring social capital: A synthesis of findings and recommendations from Social Capital Iniciative. Social Capital Iniciative. World Bank, working paper n. 24. www.worldbank.org/socialdevelopment, 2001.

GUILLEN, Mauro F. Is globalization civilizing, destructive or feble? A critique of five key debates in the social science literature. Annual Review of Sociology, 27, p. 235-259, 2001.

HABERMAS, Jurgen. Mudança estrutural da esfera pública: investigações quanto a uma categoria da sociedade burguesa. (Trad. Flávio R. Kothe). Rio de Janeiro: Tempo Brasileiro, (1984), 1961.

HALAL, William E. e TAYLOR, Kenneth B. 21 century economics: syntesis of economic progressive thought. Business and Society Review. New York: v. 107, n.2, p.255-275, Summer 2002.

HANSSON, Finn, HUSTED, Kenneth e VESTERGAARD, Jakob. Second generation science parks: from structural holes jockeys to social capital catalysts of the knowledge society. Technovation, vol. 25, issue 9, p.1039-1049, September 2005.

HISRT, Paul e THOMPSON, Grahame (1998)[1996]. Globalização em questão. Trad. Wanda Caldeira Brant. Petrópolis: Vozes, p.364

HYDEN, Goran. Civil society, social capital, and development: dissection of a complex discourse. Studies in Comparative International Development, vol. 32, n. 1, p.3-30, spring 1997.

JACOBS, Ronald N. Civil society and crisis: culture, discourse, and the Rodney King beating. American Journal of Sociology, 101, 5, p.1238-72, march 1996.

JCS. The fragmentarion of sociology. Journal of Classical Sociology, vol.1, 1, p.5$12,2001$. 
KEYNES, John M. Teoria general de la ocupacion, el interes y el dinero. (Trad.Eduardo Hornedo). México: Fondo de Cultura Econômica, (1943), 1936.

KRIMSKY, Sheldon and GOLDING, Dominique. Social theories of risk. Westport, Connecticut, London: Praeger Publishers, 1992.

LASH. Scoot and URRY, John. The end of organized capitalism. Madison, University of Wisconsin Press, 1987.

LEMERT, Charles. Social theory. The multicultural and classic readings. Oxford: Westview Press, ed. 1999.

LIEBESKIND, Julia Porter. Knowledge, strategy, and the theory of the firm. Strategic Management Journal, vol. 17, p.93-107, Winter Special Issue, 1996.

LINDENBERG, Siegwart. Institutional design and its discontent: Coleman's neglect of social rationality. Center for Studies of Economy \& Society, Working Papers (Paper \# 14), http://www.economyandsociety.org/publications/, November 1993.

LIPSET, Seymour Martin. American excepcionalism. A double-edged sword. New York, London, W.W. Norton \& Company, (1997), 1996.

MAGNUSON, Eric. Ideological conflict in american political culture: the discurse of civil society and american national narratives in american history textbooks. The International Journal of Sociology and Social Policy, 17,6, p.84-130, 1997.

MARX, Karl. El capital. Crítica de la economía política. (Trad.Wenceslao Roces). México: Fondo de Cultura Económica, 3 v, (1946), 1867.

MARX, Karl. Elementos fundamentales para la critica de la economía política (Grundrisse) 1857-1858. (Trad. Pedro Scaron). México: Siglo XXI, 3 vols, (1982).

MASKELL, Peter. Social capital, innovation and competitiveness. In: BARON, Stephen, FIELD, John \& SCHULLER, Tom. Social capital. Critical Perpectives. Oxford: Oxford University Press, p. 111-124, 2000.

MELMAN, Seymour. From private for state capitalism: how the permanent war economy transformed the institutions of american capitalism. Journal of Economic Issues, 2, p.311-330, june 1997.

MICHELS, Robert. Sociologia dos partidos políticos. (Trad. Arthur Chaudon). Brasília: Editora da Universidade de Brasília, (1982), 1914. 
MIZRUCHI, Mark S. Berle e Means revisited: the governance and power of large US corporations. Theory and Society, 33: 579-617, 2004.

MONSEN, R. Joseph. The future of american capitalism. California Management Review, 21. 3, p.5-16, Spring 1979.

MOODY, James (2004) The estructure of social science colaboration networks: disciplinary cohesion from 1963 to 1999. American Sociological Review, 69, 2, p.213-238, april 2004.

NACIONAL RESEARCH COUNCIL. Committee on Intellectual Property Rights and the Emerging Information Infrastructure. The Digital Dilemma. Intellectual Property in the Information Age, National Academy Press, Washington DC, 2000.

NAHAPIET, Janine \& GHOSHAL, Sumantra. Social capital, intellectual capital and organizational advantage. The Academy of Management Review, vol. 23, n. 2, p.242-266, apr. 1998.

NAKAMURA, Leonard (2000) Economics and new economy: the invisible hand meets creative destruction. Business Review - Federal Reserve Bank of Philadelphia, p. 15-28, jul/ago 2000.

NERDRUM, Lars. Intellectual capital: a human capital perspective. Journal of Intellectual Capital, vol.2. n. 2. pp. 127-135, 2001.

OEHMKE, James F. \& SCHIMMELPFENNIG, David E. Quantifying structural change in U.S. agriculture: the case of research and productivity. Journal of Productivity Analysis, vol.21, n.3, p.297-320, may 2004.

OFFE, Claus (1989)[1985]. Capitalismo desorganizado. (Trad. Wanda Caldeira Brant). São Paulo: Ed. Brasiliense, (1989), 1985.

OWEN, David. Sociology after postmodernism. London, Sage, 1997.

PERELMAN, Michael. The political economy of intellectual property. Monthly Review, 54, n. 8, p.29-37, 2003 a.

PERELMAN, Michael. Intellectual property rights and the commodity form: new dimensions in the legislated transfer of surplus value. Review of Radical Political Economics, vol. 35, n. 3, p.304-311, summer 2003 b. 
PIAZZA-GEORGI, Barbara. The role of human capital and social capital in growth: extending our understading. Cambridge Journal of Economics, 26, n.4, p.461479, 2002.

PINE II, B. Joseph. Personalizando Produtos e Serviços. Customização Maciça, a Nova Fronteira da Competição nos Negócios. S.Paulo, Makron Books do Brasil, 1994.

PORTES, Alejandro, Social capital: its origins and applications in modern sociology. Annual Review of Sociology, 24, p.1-24, 1998.

PUTNAM, Robert D., LEONARDI, Robert e NANETTI, Raffaella. Comunidade e democracia, a experiência da Itália moderna. 3aed. (Trad.Luiz Alberto Monjardim) Rio de Janeiro: Fundação Getúlio Vargas, (2002), 1993.

PUTNAM, Robert D. Bowling alone: the collapse and revival of american community. New York: Simon \& Schuster, (2000), 1995.

RENN, Ortwin. Concepts of risk: a classification. In KRIMSKY, Sheldon \& GOLDING, Dominique. Social theories of risk. Westport, Connecticut, London, Praeger Publishers, p.53-79, 1992.

ROMER, Paul. Increasing Returns and Long Run Growth, Journal of Political Economy 94, 1002-37, October 1986.

ROMER, Paul. Human capital and growth: theory and evidence. National Bureau of Economic Research, working paper n. 3173, p.51, November 1989.

ROMER, Paul. Endogenous Technological Change, Journal of Political Economy 98, S71-S102, October 1990.

ROUTLEDGE, Bryan R. \& AMSBERG, Joachim von. Social capital and growth. Journal of Monetary Economics, 50 (2003), p.167-193, 2002.

SAINT-ONGE, Hubert. Tacit knowledge. The key to strategic alignment of intellectual capital. Strategy \& Leadership, 24, 2, pp. 10-14, mar/apr. 1996.

SCHUMPETER, Joseph A. Capitalism, socialism and democracy. London, Routledge, (1996), 1943.

SKLAIR, Leslie. Sociologia do sistema global. (Trad. Reinaldo Endlich Orth). Petrópolis: Vozes, (1995), 1990. 
SKLAIR, Leslie. The transnational capitalist class and global politics: deconstructing the corporate-state connection. International Political Science Review, vol. 23, n. 2, p.159-174, 2002.

SKOCPOL, Theda. Diminished democracy. From membership to management in american civic life. Norman: University of Oklahoma Press, 2003.

SMELSER, Neil J. Looking back at 25 years of sociology and the Annual Review of Sociology. Annual Review of Sociology. 25: 1-18, 1999.

SMITH, Adam. Inquérito sobre a natureza e as causas da riqueza das nações.(Trad. Teodora Cardoso e Luís Cristóvão de Aguiar). Lisboa: Fundação Calouste Gulbenkian, 2 vols, (1981), 1776.

SPENDER, J-C. Making knowledge the basis of a dynamic theory of the firm. Strategic Management Journal, vol. 17, p.45-62, Winter Special Issue, 1996.

SPENDER, J-C. e GRANT, Robert M. Knowledge and the firm: Overview. Strategic Management Journal, vol. 17, Winter Special Issue, p.5-9, 1996.

STEWART, Thomas A. Capital intellectual. A nova vantagem competitiva das empresas. (Trad. Ana Beatriz Rodrigues, Priscilla Martins Celeste). Rio de Janeiro: Campus, (1998), 1997.

STINCHCOMBE, Arthur, et alii. Review Essay Symposium. Theory and Society, v. 21/2, p.183-283, 1992.

SWEDBERG, Richard. Vers une nouvelle sociologie economique: bilan et perspectives. Cahiers Internationaux de Sociologie. Vol. CIII, nouvelle série, 48eme année, p.237-263, juillet-decembre 1997.

SWEDBERG, Richard. Max Weber and the idea of economic sociology. Princeton, N.Jersey, Princeton University Press, 1998.

TAYLOR, Charles. Liberal politics and the public sphere.. In ETZIONI, Amitai. New communitarian thinking: persons, virtues, institutions and communities. Charlotesville, University Press of Virginia. P.183-217, dx. 1995.

TILMAN, Rick. Apology and ambiguity: Adolf Berle on corporate power. Journal of economic Issues, vol. Viii, n. 1, p.111-126, march 1974.

THUROW, Lester. Needed: a new system of intellectual property rights. Harvard Business Review, v. 75, n. 5, p.94-104, setp-oct 1997. 
THUROW, Lester. Globalization: the product of a knowledge-based economy. The Annals of the American Academy, 570, p.19-31, july 2000.

TUOMELA, Raimo. Corporate intention and corporate action. Analyse und Kritik. 15, p.11-21, 1993.

ULRICH, Dave. Intellectual capital = competence and commitment. Sloan Management Review, 39, 2 pp.15-26, winter 1998.

UZUNIDIS, Dimitri e LAPERCHE, Blandine. Strategies entrepreneuriales et appropriation de l'information scientifique et technique. La Pensee, n. 311, p.8194, juil-sept 1997.

WOOLCOCK, Michael. Social capital and economic development: toward a theoretical synthesis and policy framework. Theory and Society, 27: 151-208, 1998.

WOOLCOCK, Michael and NARAYAN, Deepa. Social capital: implications for development theory, research and policy. The World Bank Research Observer, vol 15 n. 2, p.225-249, august 2000. 


\section{Resumo:}

O trabalho examina o movimento intelectual que envolveu a reflexão científica nas ciências sociais a partir dos anos 1960 e suas vinculações com as transformações que, na mesma época, agitam as relações econômicas e políticas no plano mundial, com seu foco principal apontado para os Estados Unidos. Duas das expressões mais significativas desse movimento são localizadas em questões relativas à identificação de uma crise institucional na democracia americana e com a verificação do processo de reavaliação do papel da Sociologia, seja desde o ponto de vista institucional, seja como instrumento de explicação da realidade social do país e do mundo. A crise política americana é visualizada como tendo por pano de fundo a reorganização do poder econômico do país, resultante do desenvolvimento tecnológico e do processo de globalização. A partir da constatação de que os fundamentos da democracia americana parecem estar ameaçados por mudanças comportamentais e estruturais internas, desenvolve-se no país considerável quantidade de pesquisas e estudos abordando diferentes perspectivas da atuação das grandes corporações. Como contraponto à percepção da degradação da comunidade política interna, esse esforço é marcadamente orientado para a identificação dos compromissos do circuito empresarial com o comportamento cívico e com a democracia, quer na afirmação da ética nos negócios, quer na perspectiva do desenvolvimento de uma política social mais compatível com as estratégias corporativas. Este é o contexto em que a noção de capital social adquire o sentido de articulador principal das disputas políticas e teóricas em torno do desenvolvimento econômico e das transformações verificadas na atividade industrial resultantes da expansão de novas tecnologias e de seus efeitos em termos da necessidade de redimensionamento do direito de propriedade intelectual.

Palavras-chave: Teoria sociológica, corporação, revolução tecnológica, capital social, propriedade intelectual.

Recebido: 19/11/2005

Aceite final: 06/06/2006 


\section{Social capital and the privatization of knowledge}

\section{Renato P. Saul}

This work examines the intellectual movement that dominated the scientific thought in the social sciences from the 1960s onwards, and its connection with the changes in the world's economic and political relations since then, emphasizing the United States. Two of the most significant manifestations of this movement are found in questions related to the identification of an institutional crisis in American democracy and the need for a process to re-evaluate the role of sociology, both from the institutional point of view, and as a tool to explain the social reality of the country and the world. The reorganization of America's economic power, as a result of the technological development and the globalization process, provides the background for the political crisis in the United States. When it becomes evident that the foundations of the American democracy are threatened by changes in its internal structure and behavior, it is possible to detect the development of a considerable amount of research and studies dealing with different perspectives of the large corporations' activities. As a counterpoint to the apparent deterioration of the internal political community, this effort intends to identify the commitments of the business circuit with the civic behavior and democracy, whether in the assertion of ethics in business, or in the perspective of the development of a social policy more compatible with the corporate strategies. It is in this context that the concept of social capital becomes the main articulator of political and theoretical disputes on the subject of the economic development and the changes verified in the industrial sector resulting from the expansion of new technologies and their effects regarding the need for a redimensioning of the intellectual property right.

Keywords: Sociological theory, corporation, technological revolution, social capital, intellectual property. 